\title{
Is distortion of the bioprosthesis ring a risk factor for early calcification?
}

Jose Manuel Martinez Cereijo ${ }^{1}$, Jose Rubio Alvarez ${ }^{1 *}$, Juan Sierra Quiroga', Anxo Martinez de Alegria², Jose Manuel Suarez Peñaranda ${ }^{3}$

\begin{abstract}
Background: As the population ages, bioprosthesis are increasingly being used in cardiac valve replacement. Pericardial bioprosthesis combine an excellent hemodynamic performance with low thrombogenicity, but valve failure associated with calcification remains a concern with these valves. We describe distortion of the bioprosthesis ring as a risk factor for early calcification.

Methods: A total of 510 patients over the age of 70 years underwent isolated aortic valve replacement with the Mitroflow (A12) pericardial bioprosthesis. Thirty two patients $(6,2 \%)$ have undergone a second aortic valve replacement due to structural valve dysfunction resulting from valve calcification. In all patients a chest radiography and coronary angiography was performed before reoperation. A 64 Multidetector Computed Tomography (MDCT) with retrospective ECG gating study was performed in four patients to evaluate the aortic bioprosthesis.
\end{abstract}

Results: Chest radiography showed in all patients an irregular bioprosthesis ring. At preoperative coronary angiography a distorted bioprosthesis ring was detected in all patients. Macroscopic findings of the explanted bioprostheses included extensive calcification in all specimens.

Conclusion: There was a possible relationship between early bioprosthetic calcification and radiologic distortion of the bioprosthesis ring.

As the population ages, bioprosthesis are increasingly being used in cardiac valve replacement. Pericardial bioprosthesis combine an excellent hemodynamic performance [1] with low thrombogenicity [2], but valve failure associated with calcification remains a concern with these valves [3]. We describe distortion of the bioprosthesis ring as a risk factor for early calcification.

\section{Materials and methods}

A total of 510 patients over the age of 70 years underwent isolated aortic valve replacement with the Mitroflow (A12) pericardial bioprosthesis at our hospital. Sixty-five percent of patients undergoing aortic valve replacement received a $21 \mathrm{~mm}$ valve. Demographic data at time of reoperation are listed in Table 1 and the size of the bioprosthesis in Table 2 To date 32 patients $(6,2 \%)$ have undergone a second aortic valve replacement due to

\footnotetext{
* Correspondence: jose.rubio.alvarez@sergas.es

1 Department of Cardiovascular Surgery, Santiago de Compostela University

Hospital. La Choupana, Santiago de Compostela 15706, Spain

Full list of author information is available at the end of the article
}

structural valve dysfunction (SVD) resulting from valve calcification. The mean time between the first operation and reoperation was 70 months (range 36 to 98 months).

In all patients a chest radiography and coronary angiography was performed before reoperation.

A 64 Multidetector Computed Tomography (MDCT) with retrospective ECG gating study was performed in four patients to evaluate the aortic bioprosthesis. In two patients the study was performed three weeks after aortic valve replacement with the Mitroflow A12 pericardial bioprosthesis. Both bioprosthesis were normal by echocardiographic study. Another two patients had bioprosthesis with SVD.

A Histopathologic analysis of the removed bioprosthesis was performed by one experienced pathologist.

\section{Results}

Macroscopic findings of the explanted bioprostheses included extensive calcification in all specimens. In all cases, one leaflet was more calcified than the others; in
C Biomed Central 


\section{Table 1 Demographic data}

\begin{tabular}{lc}
\hline Age (range) & $77 \pm 4(71-86)$ \\
Female/Male & $18 / 14$ \\
Aortic Stenosis & $28(87,5 \%)$ \\
Renal insufficiency & 0 \\
Hypertension & $14(43,7 \%)$ \\
Diabetes & $2(6,25 \%)$ \\
\hline
\end{tabular}

our experience, the right coronary leaflet was commonly the most calcified (19/32. 59,3\%).

In all patients, serum levels of cholesterol, triglycerides, lipoprotein A and calcium were within the normal range. No patients were treated with calcium supplementation.

Chest radiography (Figure 1) showed in all patients an irregular, non- circular bioprosthesis ring. At preoperative coronary angiography a distorted bioprosthesis ring was detected in all patients (Figure 2). An explanted bioprosthesis with leaflet distortion and right coronary leaflet calcification is shown in Figure 3.

In two patients with normal bioprosthesis, the morphology of the leaflets and the degree of excursion were normal at MDCT, but a leaflet had a wave movement. The distorted ring was observed in these patients (Figure 4) and the same picture was observed in two patients with SVD.

The percentage of distortion of the bioprosthesis ring in patients without SVD was $76 \%$, but no all patients had the same degree of distortion.

\section{Discussion}

Bioprosthetic calcification is a multifactorial process; contributing factors include the type of implant used, mechanical stress, preservation method, patient age and technical correctness of the implantation procedure [4]. The rate of structural valve dysfunction is lower in elderly patients and early calcification in this group of patients is an uncommon event.

There is a strong relationship between mechanical stress and calcification in bioprosthesis $[4,5]$; in our study we noted that early calcification tended to develop in patients with radiologic distortion of the bioprosthesis ring. Liao and colleagues [4] observed similar results with bioprostheses removed from left ventricular assist devices. Distortion of the bioprosthesis ring may be due to technical problems at implantation [6] or compression

Table 2 Bioprosthesis size

\begin{tabular}{lc}
\hline Valve Size $(\mathrm{mm})$ & At reoperation \\
\hline 19 & 1 \\
21 & 20 \\
23 & 10 \\
25 & 1 \\
\hline
\end{tabular}

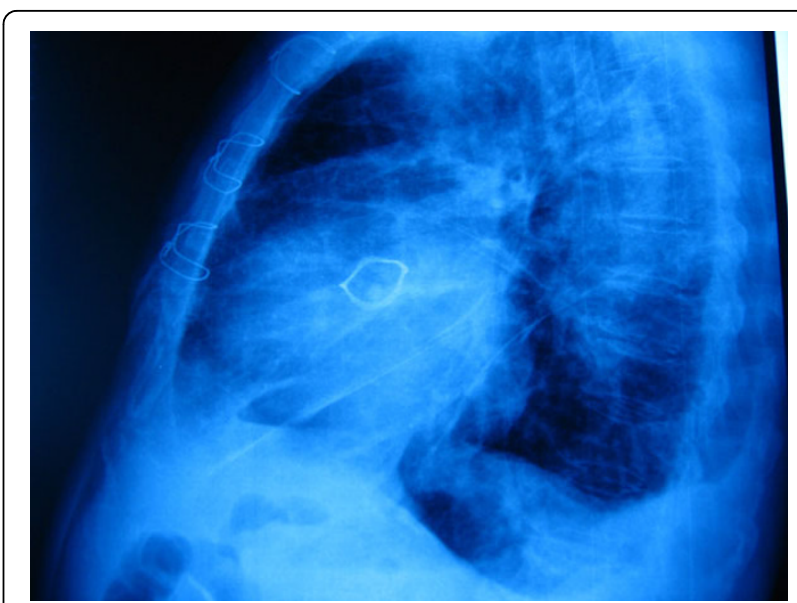

Figure 1 Radiographic evaluation showed a misshapen bioprosthesis ring.

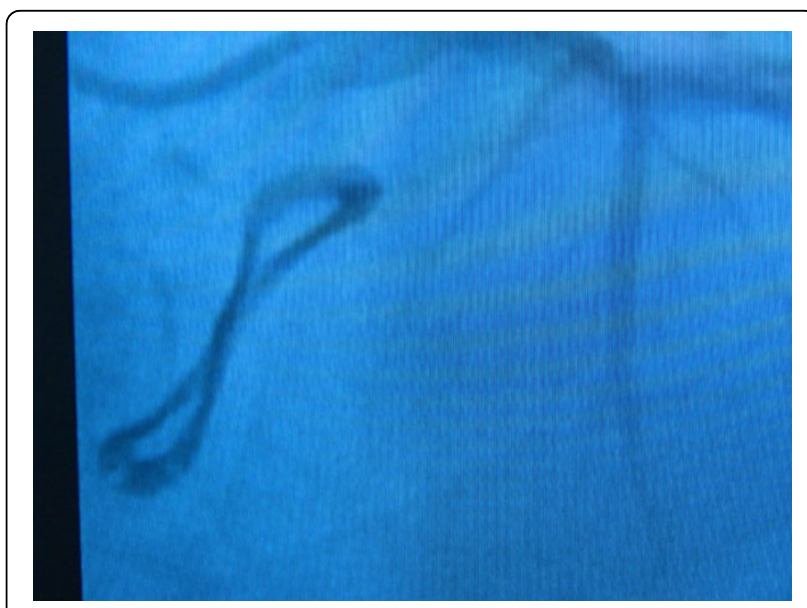

Figure 2 Preoperative coronary angiography showed a misshapen bioprosthesis ring.

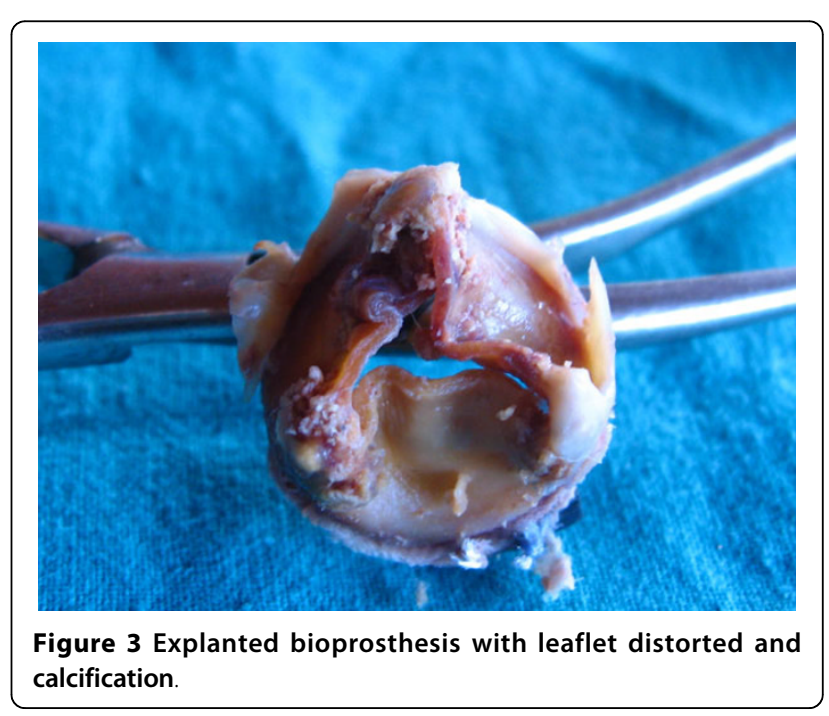




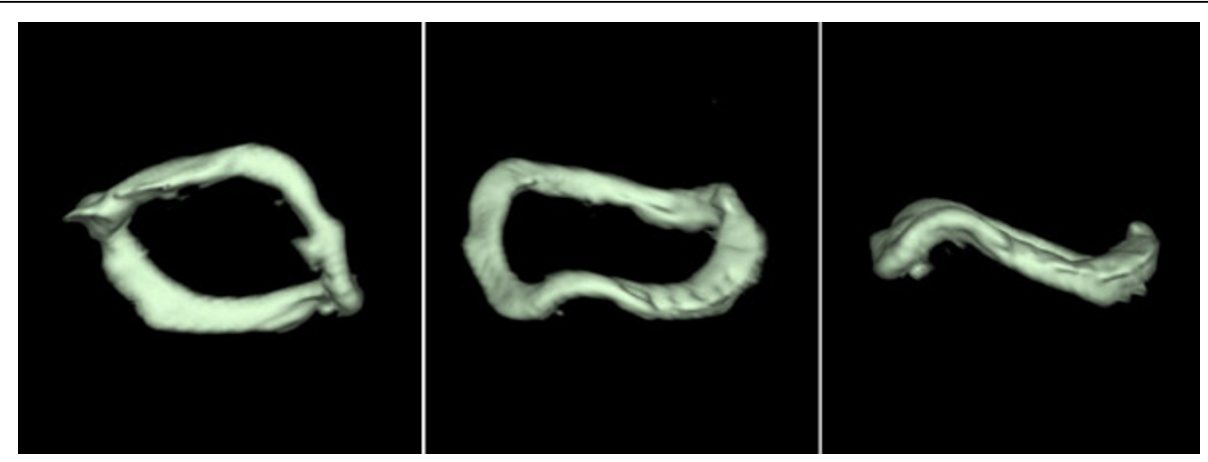

Figure 4 Three different views of the bioprosthesis ring at MDCT.

around the ring. However we speculate that Dacron ring traction from the annular stitch may distort the normal planar geometry of Mitroflow pericardial bioprosthesis, leading to distortion of the pericardial leaflet mounted outside the stent and fixed to the Dacron ring, resulting in a higher mechanical stress.

In our patients other casual relationship was no found.

\section{Conclusion}

In our experience there was a possible relationship between bioprosthetic calcification and radiologic distortion of the bioprosthesis ring.

\section{Author details}

'Department of Cardiovascular Surgery, Santiago de Compostela University Hospital. La Choupana, Santiago de Compostela 15706, Spain. ²Department of Radiology, Santiago de Compostela University Hospital. La Choupana, Santiago de Compostela 15706, Spain. ${ }^{3}$ Department of Pathology, Santiago de Compostela University Hospital. La Choupana, Santiago de Compostela 15706, Spain.

\section{Authors' contributions}

JMMC drafted the manuscript and did the patients follow-up.

JRA conceived of the study and participated in its design and coordination.

JSQ participated in the design of the study.

AMA carried out the radiologic studies.

JMSP carried out the pathologic studies.

All authors read and approved the final manuscript.

\section{Competing interests}

The authors declare that they have no competing interests.

Received: 13 April 2010 Accepted: 7 October 2010

Published: 7 October 2010

\section{References}

1. Bengochea JG, Sierra J, Gonzalez - Juanatey JR, Rubio J, Vega M, Fernandez AL, Sanchez D: Left ventricular mass regressión after aortic valve replacement with the new Mitroflow 12 A pericardial bioprosthesis. J Heart Valve Dis 2006, 15:446-452.

2. Corbineau H, De la Tour B, Verhoye JP, Langanay Th, Lelong B, Leguerrier A: Carpentier-Edwards supraannular porcine bioprosthesis in aortic position: 16-year experience. Ann Thorac Surg 2001, 71:S228-S231.

3. Rubio J, Sierra J, Vega M, Adrio B, Martinez Comendador JM, Gude F, Martinez Cereijo JM, Garcia J: Early calcification of the aortic Mitroflow pericardial bioprosthesis in the elderly. Interact Cardio Vasc Thorac Surg 2009, 9:842-846.
4. Liao KK, Li X, Ranjit J, Amayta DM, Joyce LD, Park SJ, Bianco R, Bolman RM: Mechanical stress: An independent determinant of early bioprosthetic calcification in humans. Ann Thorac Surg 2008, 86:491-495.

5. Bernacca GM, Fisher AC, Wilkinson R, Mackay TG, Wheatley D: Calcification and stress distribution in bovine pericardial heart valves. $J$ Biomed Mater Res 1992, 26:959-966.

6. Saunders PC, Grossi EA, Esposito RA, Bizekis CS, Strong MD, Colvin SB: Failure of four bovine pericardial mitral prostheses. J Thorac Cardiovasc Surg 2004, 127:267-268.

doi:10.1186/1749-8090-5-77

Cite this article as: Cereijo et al:: Is distortion of the bioprosthesis ring a risk factor for early calcification?. Journal of Cardiothoracic Surgery 2010 $5: 77$.

\section{Submit your next manuscript to BioMed Central and take full advantage of:}

- Convenient online submission

- Thorough peer review

- No space constraints or color figure charges

- Immediate publication on acceptance

- Inclusion in PubMed, CAS, Scopus and Google Scholar

- Research which is freely available for redistribution 